\title{
Production, purification and characterization of halophilic organic solvent tolerant protease from marine crustacean shell wastes and its efficacy on deproteinization
}

\author{
Thirumalai Maruthiah ${ }^{1} \cdot$ Beena Somanath ${ }^{2} \cdot$ Jebamonydhas Vijila Jasmin $^{3}$ • \\ Grasian Immanuel $^{1} \cdot$ Arunachalam Palavesam $^{4}$
}

Received: 30 March 2016/Accepted: 19 July 2016/Published online: 26 July 2016

(c) The Author(s) 2016. This article is published with open access at Springerlink.com

\begin{abstract}
The quantum of marine fish wastes produced by fish processing industries has necessitated to search new methods for its disposal. Hence, this study is focused on production and purification of halophilic organic solvent tolerant protease (HOSP) from marine Alcaligenes faecalis APCMST-MKW6 using marine shell wastes as substrate. The candidate bacterium was isolated from the marine sediment of Manakudi coast and identified as A. faecalis APCMST-MKW6. The purified protease showed 16.39fold purity, $70.34 \mathrm{U} / \mathrm{mg}$ specific activity with $21.67 \%$ yield. The molecular weight of the purified alkaline protease was $49 \mathrm{kDa}$. This purified protease registered maximum activity at $\mathrm{pH} 9$ and it was stable between $\mathrm{pH} 8-9$ after $1.30 \mathrm{~h}$ of incubation. The optimum temperature registered was $60{ }^{\circ} \mathrm{C}$ and it was stable between 50 and $60{ }^{\circ} \mathrm{C}$ even after $1.30 \mathrm{~h}$ of incubation. This enzyme also showed maximum activity at $20 \% \mathrm{NaCl}$ concentration. Further, manganese chloride, magnesium chloride, calcium chloride and barium chloride influenced this enzyme activity remarkably and it was also found to be enhanced by many of the tested surfactants and solvents. The candidate
\end{abstract}

Arunachalam Palavesam

plavesh06@gmail.com

1 Centre for Marine Science and Technology, Manonmaniam Sundaranar University, Rajakkamangalam, Kanyakumari 629 502, Tamilnadu, India

2 Department of Zoology, Rani Anna Government College for Women, Manonmaniam Sundaranar University, Tirunelveli 627 012, Tamilnadu, India

3 Department of Zoology, Muslim Arts College, Thiruvithancode, Kanyakumari 629 174, Tamilnadu, India

4 Department of Animal Science, Manonmaniam Sundaranar University, Tirunelveli 627 012, Tamilnadu, India bacterium effectively deproteinized the shrimp shell waste compared to the other tested crustaceans shell wastes and also attained maximum antioxidant activity.

Keywords Halophilic organic solvent tolerant protease · Marine crustacean shell wastes - Stain removal . Deproteinization · Antioxidants

\section{Introduction}

Halophilic organic solvent tolerant bacteria are one of the most important groups involved in the extremophiles field. Among this, bacterial proteins from the relevant bacteria tolerate well in different concentrations of salts and organic solvents due to their extreme characteristics. As of now halophilic tolerant proteins are received much attention in industrial sectors due to their applied extreme potentials. The specific advantages of the halophilic organic solvent tolerant proteases are; cell enlargement, strengthening of cell membrane, degradation and biotransformation of organic solvents and solvent efflux pump (Rahman et al. 2006). Also proteases that can mediate catalysis in non aqueous solvents tender new possibilities, such as shifting of thermodynamic balance in favor of synthesis, improving the solubility of hydrophobic substrates and products, facilitating the product recovery, and improving the thermal stability of the enzymes (Doukyu and Ogino 2010). Among the microbial proteases, alkaline proteases occupy $60 \%$ of the total world enzyme production, with specific applications in bakery, brewing, detergent, diagnostic reagents, feeds modification, leather finishing, laundry additives, pharmaceuticals, and peptide synthesis, silk, silver recovery from X-ray/photographic film, soy processing, and waste treatment (Rajkumar et al. 2011). 
Marine industry generates $50-60 \%$ of the total weight of shellfish as waste consists of protein (35-50\%), chitin (15-25\% of dry weight) and inorganic compound (calcium carbonate) which are considered as major environmental pollutants due to uncontrolled dumping (Islam et al. 2004; Sachindra et al. 2005). Bioconversion of these materials has been proposed as waste treatment alternate to the disposal of shellfish wastes. The utilization of these wastes not only solves the environmental problem but also decreases the production costs of microbial proteases. Halophilic solvent-tolerant bacteria make up a group of microorganisms are becoming more popular in academia and industry, due to their unique ability to live in presence of organic solvents. Some of these bacteria have been found to produce haloalkaline as well as solvent-tolerant enzymes, but only a few reports are available regarding the purification and characterization of the halophilic organic solvent-tolerant protease (Annamalai et al. 2012, 2014a, b; Maruthiah et al. 2014, 2015).

The bioconversion of marine shell wastes by various marine coastal proteolytic bacterial species was reported by several authors (Annamalai et al. 2012, 2014a, b; Maruthiah et al. 2014, 2015). However, the application of Bacillus sp. for the deproteinization of marine crustacean wastes is rarely seen. In this study, the protease-producing Bacillus sp. can be used for deproteinization of crustacean wastes. Generally, the preparation of chitin from various crustacean shells involves demineralization and deproteinization with the use of strong acids or bases. Typically to overcome the scarcity of the chemical treatments, microorganisms and proteolytic enzymes were effectively used to deproteinze the crustacean wastes (Jellouli et al. 2011; Haddar et al. 2011; Ghorbel-Bellaaj et al. 2012; Maruthiah et al. 2015; Hajji et al. 2015). Considering the above facts discussed in this study, an attempt has been made on the production and purification of the HOSP from the coastal sedimentary bacterium using marine shell wastes. Further, the candidate strain also performed maximum deproteinization and antioxidant efficiency using shrimp shell waste.

\section{Materials and methods}

\section{Marine fish waste powder preparation for HOSP production}

The shrimp shell powder (SSP), crab shell powder (CSP) and lobster shell (LSP) used in this study were prepared from the respective shell wastes collected from local fish processing units. After collection in aseptic condition, the shell wastes were washed thoroughly with tap water and sun dried. The dried materials were milled and sieved $(100 \mu \mathrm{M})$ to get uniform fine powder and used as sole carbon sources for protease production.

\section{Isolation of HOSP bacterium and culture conditions for protease production}

The candidate bacterium was isolated from the sediment sample of Manakudi coast (Lat. $8^{\circ} 05 \mathrm{~N}$ : Lon. $77^{\circ} 32^{\prime} \mathrm{E}$ ), Kanyakumari District, India and it was identified based on the morphological, physiological, and biochemical characteristics as well as $16 \mathrm{~S}$ rRNA sequencing. The isolation and identification of potent HOSP strain was followed using solvent enrichment (10\% cyclohexane and $20 \%$ sodium chloride) method (Maruthiah et al. 2014, 2015).

\section{Enzyme assay and protein estimation}

The protease assay was carried out by the method of Takami et al. (1989) using $1 \%$ casein as a substrate. The amount of protease produced was measured with the help of a tyrosine standard graph. The protein content in all the samples was estimated using Bradford method. For this study readily used Bradford reagent was used (Sigma, USA).

\section{Effect of various marine wastes on protease production}

In the investigation of suitable carbon source for protease production, growth was carried out in $250 \mathrm{ml}$ Erlenmeyer flasks with $50 \mathrm{ml}$ of basal medium containing $0.1 \%$ $\mathrm{K}_{2} \mathrm{HPO}_{4}$ and $0.05 \% \quad \mathrm{MgSO}_{4} \cdot 7 \mathrm{H}_{2} \mathrm{O}(\mathrm{pH}$ 9) and supplemented with $0.1-2 \%$ (w/v) of marine wastes to be investigated such as SSP, CSP, SPP and SCSP (Shrimp and Crab shell powder at 1:1, 1:3 and 3:1 ratio, w/w) (Maruthiah et al. 2015).

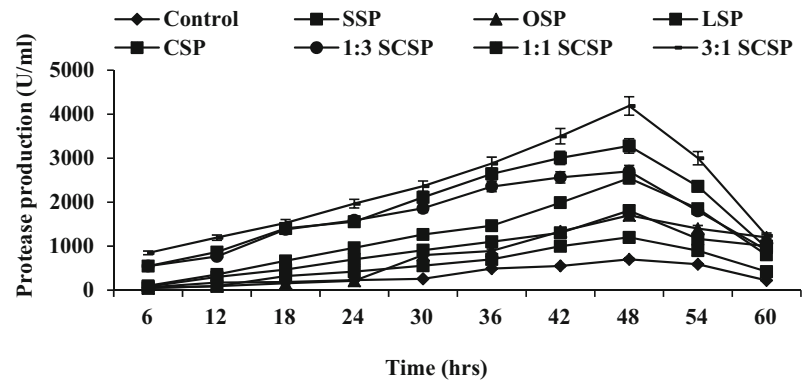

Fig. 1 Effect of protease production using marine crustacean shell waste. Each value represents the mean of three experiments and the error bars indicate $\pm \mathrm{SD}$ 


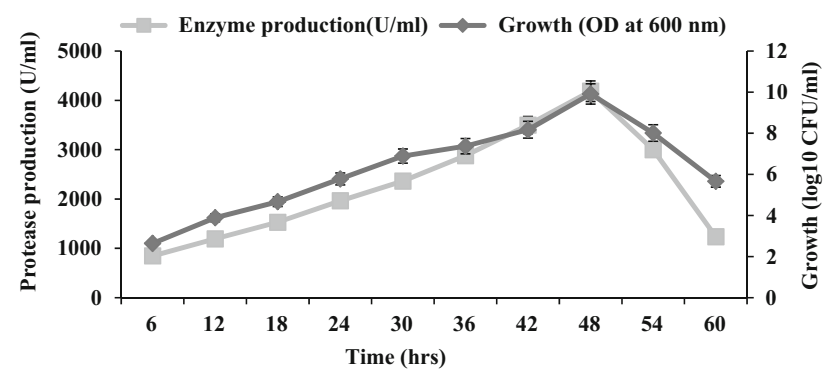

Fig. 2 Kinetics of bacterial cell growth and production of HOSP by optimized medium. Each value represents the mean of three experiments and the error bars indicate $\pm \mathrm{SD}$

\section{Production and purification of HOSP}

In the investigation of suitable carbon source for protease production, growth was carried out in $500 \mathrm{ml}$ Erlenmeyer flasks with $100 \mathrm{ml}$ of basal medium containing Shrimp and Crab shell powder $(3: 1 \mathrm{w} / \mathrm{w}), 0.1 \% \mathrm{~K}_{2} \mathrm{HPO}_{4}$ and $0.05 \%$ $\mathrm{MgSO}_{4} \cdot 7 \mathrm{H}_{2} \mathrm{O}, \mathrm{NaCl}(100.00 \mathrm{~g} / \mathrm{l})$, calcium chloride $3.0(\mathrm{~g} /$ 1) were seeded with $5 \%$ inoculum and incubated in shaking incubator $(125 \mathrm{rpm})$ for $48 \mathrm{~h}$. After incubation, the culture broth was centrifuged $\left(4{ }^{\circ} \mathrm{C}\right.$ at $12,000 \mathrm{~g}$ for $\left.20 \mathrm{~min}\right)$ and the crude enzyme was used for further purification.

\section{Purification of HOSP from A. faecalis APCMST- MKW6}

The purification starts with $75 \%$ ammonium sulphate precipitation and kept at $4{ }^{\circ} \mathrm{C}$ for $24 \mathrm{~h}$. Ammonium sulphate fractions were resuspended in minimal volume of $50 \mathrm{mM}$ Tris- $\mathrm{HCl}$ buffer $(\mathrm{pH}$ 7.2). The precipitates were collected through centrifugation at $6000 \mathrm{~g}$ for $15 \mathrm{~min}$ and dissolved in $50 \mathrm{mM}$ Tris- $\mathrm{HCl}$ buffer ( $\mathrm{pH} 9.0)$ and dialysed against same buffer $\left(4^{\circ} \mathrm{C}\right)$ for $12 \mathrm{~h}$. Then it was loaded on a DEAE-sepharose fast-flow column, pre-equilibrated with $50 \mathrm{mM}$ Tris- $\mathrm{HCl}(\mathrm{pH}$ 8.0). The unabsorbed protein fractions were eluted with the same buffer at a flow rate of $2 \mathrm{ml} / \mathrm{min}$. The protease activity of individual eluted fractions was determined. Further the fractions showing the highest protease activity were pooled together and concentrated using ultra filtration unit (Amicon $10 \mathrm{kDa}$ molecular weight cut-off device, Millipore, USA). The homogeneity and the molecular weight of the purified protease were determined by SDS-PAGE and further confirmed by zymogram analysis (Laemmli 1970; GarciaCarreno et al. 1993).

\section{Biochemical properties of purified protease}

The effect of different $\mathrm{pH}$ (4-10) and temperature $\left(30-80{ }^{\circ} \mathrm{C}\right)$ on protease activity were studied. The effect of metal ions $\left(\mathrm{MgCl}_{2}, \mathrm{CaCl}_{2}, \mathrm{ZnCl}_{2}, \mathrm{MnCl}_{2}, \mathrm{HgCl}_{2}, \mathrm{ZnSO}_{4}\right.$, $\mathrm{MnSO}_{4}$ and $\mathrm{BaCl}_{2}$ at $5 \mathrm{ppm}$ ), surfactants [poly ethylene glycol (PEG)], [sodium dodecyl sulphate (SDS)], triton $\times 100$, Tween $20,40,60$ and 80 at $5 \mathrm{mM}$ ), $\mathrm{NaCl}$ (5-25\%) inhibitor [phenyl methyl sulfonyl fluoride (PMSF), dithiothereitol (DTT)], iodoacetamide (IAA), $\beta$ mercaptoethanol and ethylene diamine tetra acetic acid (EDTA) at $5 \mathrm{mM}$ ], solvents (ethanol, methanol, hexane, acetone, DMSO, chloroform and benzene) and detergents (Ariel, Tide, Rin, Surf, Sunlight, Henko and Surf excel) were studied by following standard assay procedure (Maruthiah et al. 2014, 2015).

In the entire biochemical characterization studies, all the protease assays were performed, by the optimized temperature $\left(60{ }^{\circ} \mathrm{C}\right)$ and $\mathrm{pH}(9.0)$. All experiments were conducted in triplicate and the results are represented as the mean values.

\section{Chitin extraction biological method}

\section{Biological method of deproteinization using crustacean} shells

In the deproteinization experiment, the powdered shells from the crustaceans were individually mixed with above said halophilic production medium taken in flasks (solid to liquid ratio was 1:3 w/v) except casein acid hydrolysate, peptone and yeast extract. Then the flasks were sterilized at $121^{\circ} \mathrm{C}$ and cooled. Further the candidate proteolyitc bacterial strain (A. faecalis APCMST-MKW6) was inoculated into the flasks. The flasks were incubated at $50{ }^{\circ} \mathrm{C}$ for $3 \mathrm{~h}$. After incubation the reaction was stopped by heating the flasks for $20 \mathrm{~min}$ at $90{ }^{\circ} \mathrm{C}$. Then, it was centrifuged at $5000 \mathrm{rpm}$ for $20 \mathrm{~min}$ to separate soluble and insoluble fractions. The solid fraction was washed with distilled water and dried for $3 \mathrm{~h}$ at $60{ }^{\circ} \mathrm{C}$. After that, the mineral contents (demineralization) were removed using the $2 \mathrm{~N}$ $\mathrm{HCl}$ for $24 \mathrm{~h}$. Further, the samples were dried at $90{ }^{\circ} \mathrm{C}$ for $20 \mathrm{~min}$. From the dried materials, the protein content was estimated using the standard protocol. Results were presented as means of experiments performed in triplicate (Yang et al. 2000).

\section{Antioxidant profile}

\section{DPPH radical scavenging activity}

A volume of $500 \mu \mathrm{l}$ each of experimental samples (culture supernatant, crude protease and commercial enzyme) was individually mixed with different concentrations (w/v) of $(0.25-2.0 \mathrm{mg} / \mathrm{ml})$ dried deproteinized shrimp shell powder (maximum deproteinized crustacean shell waste) with $99.5 \%$ ethanol and $0.02 \%$ DPPH in $99.5 \%$ ethanol. Then 
the mixtures were incubated at $37{ }^{\circ} \mathrm{C}$ for $60 \mathrm{~min}$ in dark and the radical scavenging activity was measured at $517 \mathrm{~nm}$. Distilled water was used as control. Lower absorption of the reaction mixture indicates higher DPPH radical scavenging activity (Maruthiah et al. 2015).

Radical scavenging activity $(\%)=\frac{A_{\text {control }}-A_{\text {sample }}}{A_{\text {control }}} \times 100$

where $A$ is absorbance at $517 \mathrm{~nm}$. The test was carried out in triplicate.

\section{Reducing power assay}

Each sample solution (1 ml) containing deproteinized (dried) shrimp shell waste at different concentrations of $(0.25-2 \mathrm{mg} / \mathrm{ml})$ was mixed with $2.5 \mathrm{ml}$ of $0.2 \mathrm{M}$ phosphate buffer (pH 6.6) and $2.5 \mathrm{ml}$ of $1 \%(\mathrm{w} / \mathrm{v})$ potassium ferricyanide. The mixtures were then incubated for $30 \mathrm{~min}$ at $50{ }^{\circ} \mathrm{C}$, followed by the addition of $2.5 \mathrm{ml}$ of $10 \%(\mathrm{w} / \mathrm{v})$ trichloroacetic acid. The reaction mixtures were then centrifuged for $10 \mathrm{~min}$ at $10,000 \mathrm{rpm}$. Finally, $2.5 \mathrm{ml}$ aliquot of the supernatant solution, from each sample mixture was mixed with $2.5 \mathrm{ml}$ of distilled water and $0.5 \mathrm{ml}$ of $0.1 \%$ (w/v) ferric chloride. After 10 min incubation, the absorbance of the resulting solution was measured at $700 \mathrm{~nm}$. Higher absorbance of the reaction mixture indicated maximum reducing power. Values presented are the mean of triplicate analyses (Maruthiah et al. 2015).

\section{Metal chelating measurement}

A known volume $(1.1 \mathrm{ml})$ of diluted sample was mixed with $100 \mu \mathrm{l}$ of $\mathrm{FeCl} 2$. The reaction was initiated by the addition of $400 \mu \mathrm{l}$ of ferrozine, and after $10 \mathrm{~min}$ when the mixture reached equilibrium, the absorbance was read at $562 \mathrm{~nm}$. A control was maintained in the same manner, and here distilled water was used instead of sample (Maruthiah et al. 2015). The percentage of inhibition of the complex ferrozine- $\mathrm{Fe}^{2+}$ was calculated using the following equation:

Inhibition $(\%)=\frac{A_{\text {control }}-A_{\text {sample }}}{A_{\text {control }}} \times 100$

where $A$ is absorbance at $562 \mathrm{~nm}$. Results were carried out in triplicate.

\section{Stain removal}

The application of protease as a detergent additive was studied on white cotton cloth pieces $(5 \mathrm{~cm} \times 5 \mathrm{~cm})$ stained with human blood and natural colorants like green leaves, tea, coffee, chocolate, tomato, pomegranate, Greece and beetroot. After incubation at $60{ }^{\circ} \mathrm{C}$ for $30 \mathrm{~min}$, the cloth pieces were taken out, rinsed with distilled water, and dried. Visual examination of various pieces exhibited the effect of enzyme in the removal of stains. Untreated cloth pieces were taken as control (Maruthiah et al. 2015).

\section{Results and discussion}

\section{Microorganism}

The HOSP producing strain APCMST-MKW6 was isolated from marine water of Manakudi coast, Tamilnadu, India and screened for their protease activity. The morphological and biochemical, 16S rRNA gene sequence analysis were confirmed the identity of the strain MKW6 as A. faecalis APCMST-MKW6 (GenBank Accession No. KF009687). Similar to this study, limited number of reports were available for the isolation of halophilic organic solvent tolerant proteolytic bacteria from the costal sediment and sea water samples (Shah et al. 2010; Karan and Khare 2011; Sinha and Khare 2012; Raut et al. 2013; Annamalai et al. 2012, 2013, 2014a, b; Maruthiah et al. 2014, 2015).

\section{Effect of various marine wastes on protease production}

The effect of various crustacean shell wastes on protease production was carried out in basal medium at $1 \%$ concentration $(3: 1 \mathrm{w} / \mathrm{v})$. Here, maximum protease production was noticed in SSP (1987.74 U/ml) and CSP (1808.41 U/ ml) added medium. Hence, further study was performed with different ratios of shrimp and crab shell powder (SCSP). The results indicated that the protease production was maximum $(4186.65 \mathrm{U} / \mathrm{ml})$ at $3: 1 \%$ ratio of SCSP during $48 \mathrm{~h}$ of incubation and it was low in 1:1\% SCSP (3277.11 U/ml) and 1:3\% SCSP (2700.55 IU/ml) (Figs. 1, 2). In consistence with the present study, Annamalai et al. (2012, 2014a, b) and Maruthiah et al. (2014, 2015) have reported enhanced protease production by Bacillus halodurans CAS6 (3413 U/ml), Bacillus firmus CAS7 (2289 U/ $\mathrm{ml})$, Bacillus alveayuensis CAS $5(2675 \mathrm{U} / \mathrm{ml})$ and Bacillus sp. APCMST-RS7 (139 U/ml) when SCSP was used as a substrate.

\section{Purification of HOSP by A. faecalis APCMST- MKW6}

The HOSP from A. faecalis APCMST-MKW6 was purified to the homogeneity by a combination of ammonium sulphate precipitation, dialysis, ultra filtration and ion-exchange chromatography. After final purification, the protease was purified with 16.39 fold purity and the overall yield registered was $21.67 \%$. The specific activity of the purified enzyme was $70.34 \mathrm{U} / \mathrm{mg}$ (Table 1). Earlier, the 
Table 1 Summary of purification of protease produced by Alcaligenes faecalis APCMST-MKW6

\begin{tabular}{lllrrr}
\hline Purification steps & Total activity & \multicolumn{2}{l}{$\begin{array}{l}\text { Total protein } \\
(\mathrm{mg})\end{array}$} & \multicolumn{1}{l}{$\begin{array}{l}\text { Specific activity } \\
(\mathrm{U} / \mathrm{mg})\end{array}$} & Yield (\%) \\
\hline Culture filtrate & $4244.19 \pm 2.58$ & $988.14 \pm 1.08$ & $4.29 \pm 0.28$ & $100 \pm 0.00$ & $1 \pm 0.00$ \\
Ammonium sulphate precipitation & $2189.78 \pm 1.17$ & $185.19 \pm 0.87$ & $11.82 \pm 0.59$ & $51.59 \pm 1.27$ & $2.75 \pm 0.49$ \\
DEAE sepharose & $920.10 \pm 0.98$ & $13.08 \pm 0.58$ & $70.34 \pm 2.27$ & $21.67 \pm 0.60$ & $16.39 \pm 0.19$ \\
\hline
\end{tabular}

All the results were presented as the mean $\pm \mathrm{SD}$

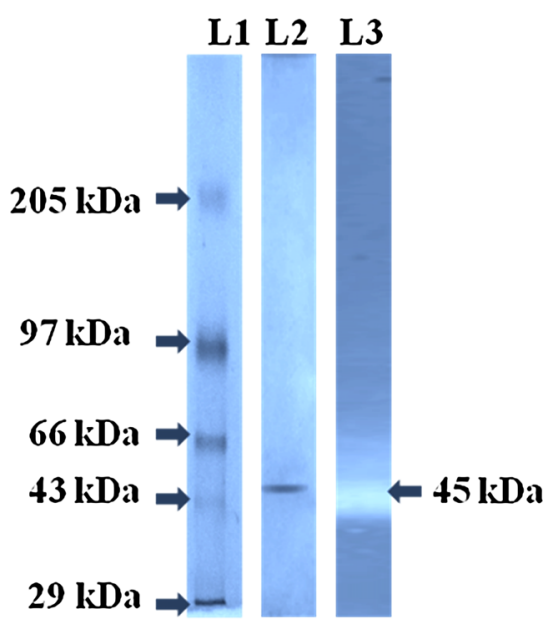

Fig. 3 SDS-PAGE analysis of purified HOSP. Lane 1-molecular weight markers. Lane 2-purified protease. Lane 3-zymography

purification and characterization of halophilic organic solvent tolerant protease from various marine coastal proteolytic bacterial species such as; B. cereus (Shah et al. 2010), Virgibacillus sp. EMB13 (Sinha and Khare 2012), B. halodurans CAS6 (Annamalai et al. 2013), B. firmus CAS 7 (Annamalai et al. 2014a, b), B. flexus APCMSTRS2 (Maruthiah et al. 2014), Bacillus sp. APCMST-RS7 (Maruthiah et al. 2015). In this study, the molecular weight of the purified protease was confirmed as $45 \mathrm{kDa}$ through SDS-PAGE and zymogram analysis (Fig. 3). Related molecular weight proteases with comparable specific activity and purity were reported from several marine aquatic halophilic organic solvent tolerant proteolytic strains such as B. flexus APCMST-RS2 $(44.3 \mathrm{kDa}), B$. alveayuensis CAS5 (33 kDa), and Bacillus sp. APCMSTRS7 (32 kDa) (Annamalai et al. 2014b; Maruthiah et al. 2014, 2015).

\section{Characterization}

In this study, the effect of optimum temperature, $\mathrm{pH}$ and $\mathrm{NaCl}$ inferred that the HOSP showed maximum activity at $60{ }^{\circ} \mathrm{C}, \mathrm{pH} 9.0$ and $20 \% \mathrm{NaCl}$ after $1.30 \mathrm{~h}$ of incubation time (Fig. 4a, b, c). Hence this protease was classified as a moderately thermoactive alkaline halophilic protease. In accordance with this study, similar kind of halophilic organic solvent tolerant proteases were previously reported from different marine bacterial species such as $B$. firmus CAS7 and B. alveayuensis CAS5 (Annamalai et al. 2014a, b). The influence of different chemicals on protease activity was also screened in this study. Among the tested chemicals $\mathrm{MnCl}_{2}$, casein, Ariel and hexane were enhanced the protease activity to the maximum level. Further, $\mathrm{MgCl}_{2}, \mathrm{CaCl}_{2}$, and $\mathrm{BaCl}_{2}$ (metal ions); SDS (surfactant); Rin and Tide (detergents) and isopropanol, acetonitrile, methanol, $N$-butanol and ethanol (solvents) were also favored the protease activity by candidate bacterium. In correlation with this study enhanced protease activity was also reported from different halophilic organic solvent tolerant Bacillus spp. Of these tested additives (Annamalai et al. 2014a, b; Maruthiah et al. 2014, 2015). Further proteases are classified based on their sensitivity to various inhibitors. In this study, the protease activity was effectively inhibited by serine (PMSF) and metalloprotease (EDTA) inhibitors and thus it evidenced that this enzyme is serine metalloprotease (Tables 2, 3, 4). This result suggested the presence of serine residue near the active site of the metalloprotease. Earlier reports also confirmed that $\beta$ mercaptoethanol and DTT stimulate the enzyme activity, suggesting that both are thiol-dependent serine proteases (Annamalai et al. 2014a, b; Maruthiah et al. 2014, 2015).

\section{Application studies}

\section{Stain removal in detergent industry}

In this study, the protease from A. faecalis APCMSTMKW6 showed better stain removal when applied with aqueous solution (Fig. 5). In agreement with this report, the halophilic proteases from various Bacillus species such as B. subtilis (Jellouli et al. 2011), B. halodurans CAS6 (Annamalai et al. 2012) and Bacillus sp. APCMST-RS7 (Maruthiah et al. 2015) also showed better efficient stain removal ability. The results explored the possibility of using the HOSP from A. faecalis APCMST-MKW6 in detergent industry. 

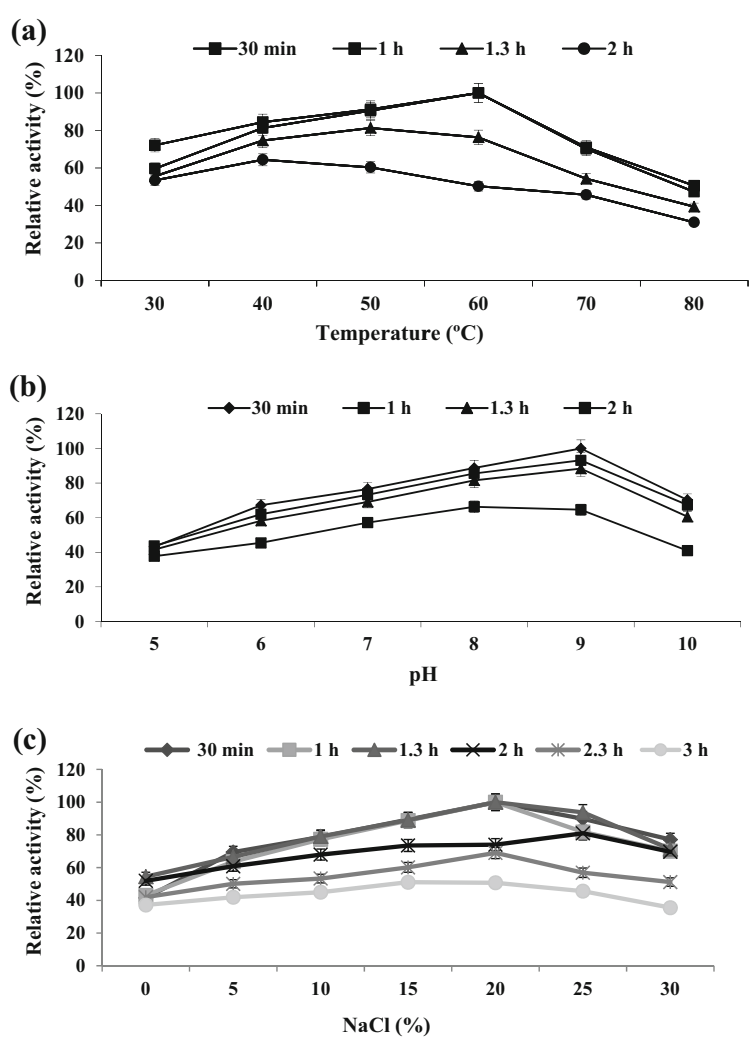

Fig. 4 Effect of physical factors on protease activity. a Effect of temperature on protease activity. b Effect of $\mathrm{pH}$ on protease activity. c Effect of $\mathrm{NaCl}$ on protease activity. Each value represents the mean of three experiments and the error bars indicate $\pm \mathrm{SD}$ )

Table 2 Effect of different metal ions and surfactants on protease activity

\begin{tabular}{lllr}
\hline Metal ions & \multicolumn{1}{l}{$\begin{array}{l}\text { Relative } \\
\text { activity }(\%)\end{array}$} & Surfactants & \multicolumn{1}{l}{$\begin{array}{l}\text { Relative } \\
\text { activity }(\%)\end{array}$} \\
\hline Barium chloride & $119.00 \pm 1.53$ & Tween 20 & $82.19 \pm 1.25$ \\
Calcium chloride & $133.47 \pm 1.66$ & Tween 40 & $91.24 \pm 1.41$ \\
Magnesium chloride & $141.12 \pm 0.85$ & Tween 80 & $153.47 \pm 1.89$ \\
Manganese chloride & $159.22 \pm 2.42$ & Triton $\times 100$ & $79.17 \pm 0.67$ \\
Mercuric chloride & $12.09 \pm 0.18$ & PEG & $34.47 \pm 0.91$ \\
Zinc chloride & $15.50 \pm 0.25$ & SDS & $118.19 \pm 1.67$ \\
Copper sulphate & $81.70 \pm 0.74$ & control & $100.00 \pm 0.00$ \\
Control & $100.00 \pm 0.00$ & & \\
\hline
\end{tabular}

$P E G$ poly ethylene glycol, $S D S$ sodium dodecyl sulphate

All the results were presented as the mean $\pm \mathrm{SD}$

\section{Marine fish waste based applications}

\section{Deproteinization by A. faecalis APCMST-MKW6}

Deproteinization is one of the most important industrial applications which was successfully carried out in this study using chemical and biological approaches.
Table 3 Effect of different inhibitors, substrate and commercial detergents on protease activity

\begin{tabular}{lr}
\hline Inhibitors & Relative activity $(\%)$ \\
\hline PMSF & $22.60 \pm 0.25$ \\
EDTA & $39.57 \pm 0.81$ \\
DTT & $144.11 \pm 1.34$ \\
Iodoacetamide & $169.43 \pm 1.55$ \\
$\beta$-mercaptoethanol & $154.17 \pm 1.39$ \\
Control & $100 \pm 0.00$ \\
Substrates & \\
Casein & $100 \pm 0.00$ \\
BSA & $31.0 \pm 0.39$ \\
Gelatin & $58.80 \pm 0.91$ \\
Commercial detergents & \\
Surf excel & $102.17 \pm 2.09$ \\
Ariel & $163.10 \pm 2.16$ \\
Tide & $119.98 \pm 1.98$ \\
Rin & $133.00 \pm 2.09$ \\
Sunlight & $117.26 \pm 2.01$ \\
Control & $100 \pm 0.00$ \\
\hline All
\end{tabular}

All the results were presented as the mean $\pm \mathrm{SD}$

Table 4 Effect of different organic solvents at two different concentrations (10 and $20 \%)$ on protease activity

\begin{tabular}{lrr}
\hline Organic solvents & \multicolumn{2}{c}{ Relative activity $(\%)$} \\
\cline { 2 - 3 } & \multicolumn{1}{c}{10} & \multicolumn{1}{c}{20} \\
\hline Isopropanol & $152.71 \pm 1.58$ & $140.20 \pm 1.20$ \\
Acetonitrile & $148 \pm 1.69$ & $139 \pm 1.68$ \\
Hexane & $174 \pm 1.58$ & $161 \pm 1.36$ \\
Benzene & $79 \pm 0.75$ & $84 \pm 0.92$ \\
$N$-butanol & $111 \pm 1.04$ & $102 \pm 1.01$ \\
Ethanol & $107 \pm 0.97$ & $119 \pm 1.09$ \\
Methanol & $131 \pm 1.32$ & $144.17 \pm 1.60$
\end{tabular}

All the results were presented as the mean \pm SD

Suggesting the efficiency of the bio-deproteinization process, the culture supernatant from A. faecalis APCMSTMKW6 was effectively deproteinized the shrimp shell to the maximum of $86.46 \%$ within 7 days of fermentation, followed by crab $(63.08 \%)$ and lobster shells $(59.07 \%)$, respectively (Fig. 6). Further it inferred that, the biological deproteinization of shrimp shell was comparable with chemical method, and it was not statistically significant $(P>0.05)$. This results find support from the earlier findings that, the different proteolytic bacterial isolates were effectively deproteinized the crustacean shell wastes in the preparation of chitin (Yang et al. 2000; Jellouli et al. 2011; Ghorbel-Bellaaj et al. 2012; Maruthiah et al. 2015; Hajji et al. 2015). The reclamation processing of crustacean shell 


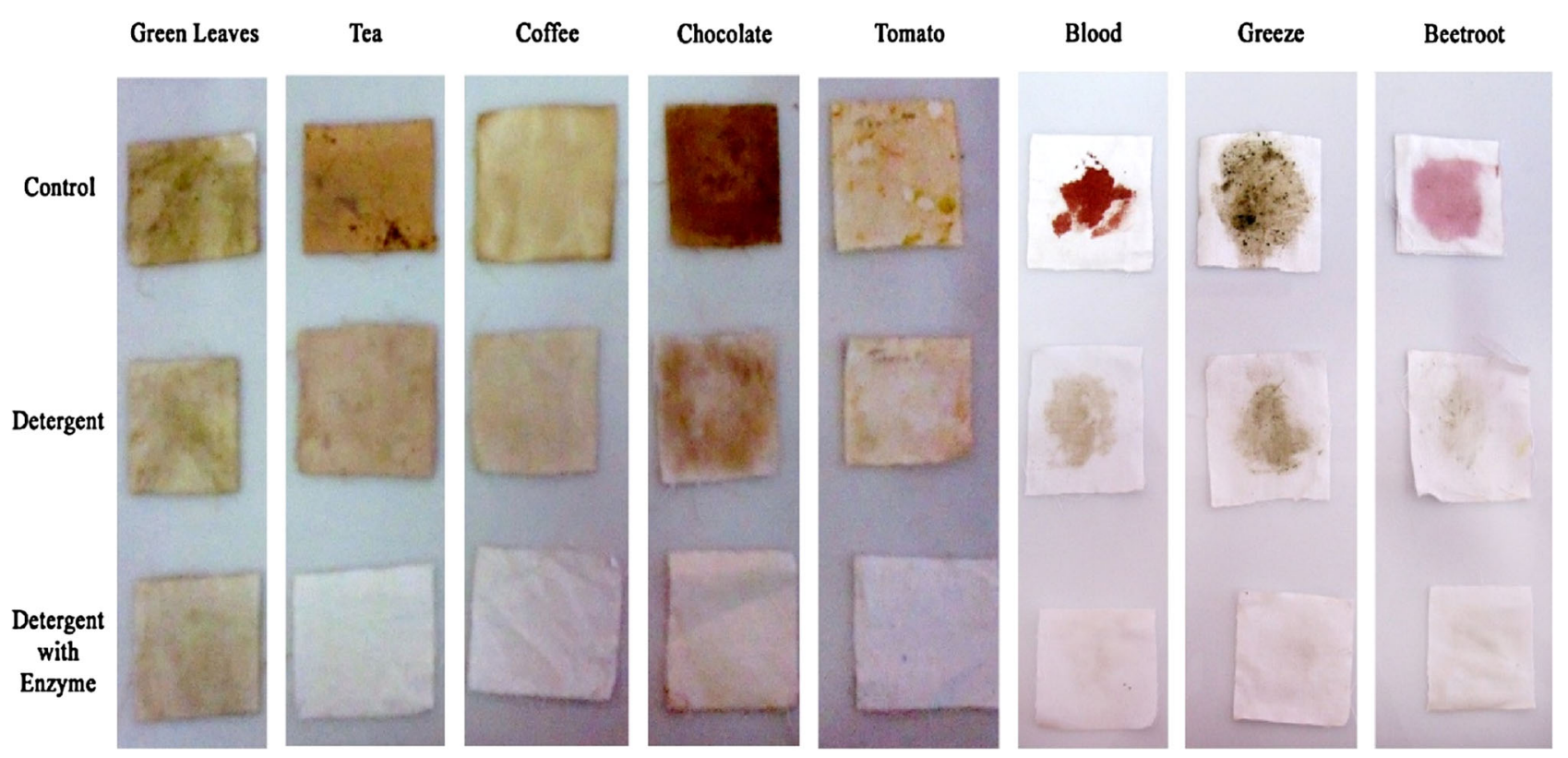

Fig. 5 Stain removal activity of the crude HOSP from Alcaligenes faecalis APCMST-MKW6. Detergent (Ariel) — $7 \mathrm{mg} / \mathrm{ml}$, crude enzyme from APCMST-MKW6-4244 U/ml

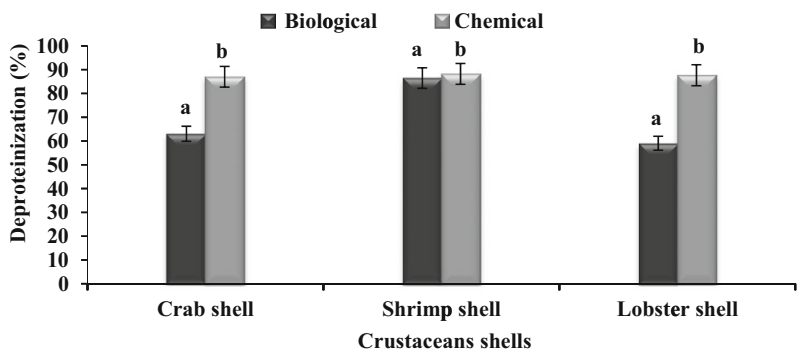

Fig. 6 Effect of deproteinization on different crustacean shells. Each value represents the mean of three experiments and the error bars indicate \pm SD. Bars having different alphabets in the respective crustacean shell wastes are statistically significant $(P<0.05)$

wastes by bioconversion emerged as an alternative solution to reduce the environmental problems associated with crustacean processing industries.

\section{Antioxiant activity (DPPH activity, reducing power and metal chelating activity)}

The antioxidant profile of the shrimp shell hydrolasate with culture supernatant, crude protease (HOSP) and commercial protease was determined. The result inferred that the maximum DPPH radical scavenging activity $(71.16 \%)$, reducing power $(\mathrm{OD}=1.63)$ and metal chelating activities (79.64\%) were recorded at $2 \mathrm{mg} / \mathrm{ml}$ concentration using shrimp shell as a substrate along with candidate marine proteolytic bacterial culture supernatant compared to the tested commercial (Alcalase) and crude protease. (Figure $7 \mathrm{a}, \mathrm{b}, \mathrm{c})$. The DPPH radical scavenging assay is a widely used method for evaluating the ability to scavenge free radicals generated from DPPH reagent. DPPH is a stable free radical, which can be reduced by a proton donating substrate such as an antioxidant, causing the decolorization of DPPH and the reduction of the absorbance at $517 \mathrm{~nm}$. The decrease in absorbance is taken as a measure for radical scavenging activity. In consistence with this study, Annamalai et al. (2012) reported the alkaline protease from B. halodurans CAS6 had attained $96 \%$ maximum antioxidant activity using shrimp shell as a substrate. Similarly, Ghorbel-Bellaaj et al. (2012) examined the hydrolysate obtained with strain A1 (B. pumilus) was found to be the most active radical-scavenger (IC50 $=0.3 \mathrm{mg} / \mathrm{ml}$ ) followed by hydrolysates obtained by strain An6 (Bacillus amyloliquefaciens), strain RP1 (Bacillus licheniformis), strain A26 (Bacillus subtilis) and strain A21 (Bacillus mojavencis), which showed comparable IC50 ranging from 0.5 to $0.6 \mathrm{mg} / \mathrm{ml}$. The highest IC50 $(1.4 \mathrm{mg} / \mathrm{ml})$ was obtained with strain SV1 (B. cereus) hydrolysate. Maruthiah et al. (2015) observed that the shrimp shell hyrolasate obtained from Bacillus sp. APCMST-RS7 showed $80 \%$ maximum DPPH radicalscavenging activity. The obtained results inferred that shrimp waste hydrolysates probably contained peptides or chitooligosaccharides, which were electron donors and could react with free radicals to convert them to more stable products and terminate the radical chain reaction (Manni et al. 2010; Ghorbel-Bellaaj et al. 2012). Thus, the fermented shrimp shell waste liquor has provided a complex mixture of compounds able to quench DPPH. 

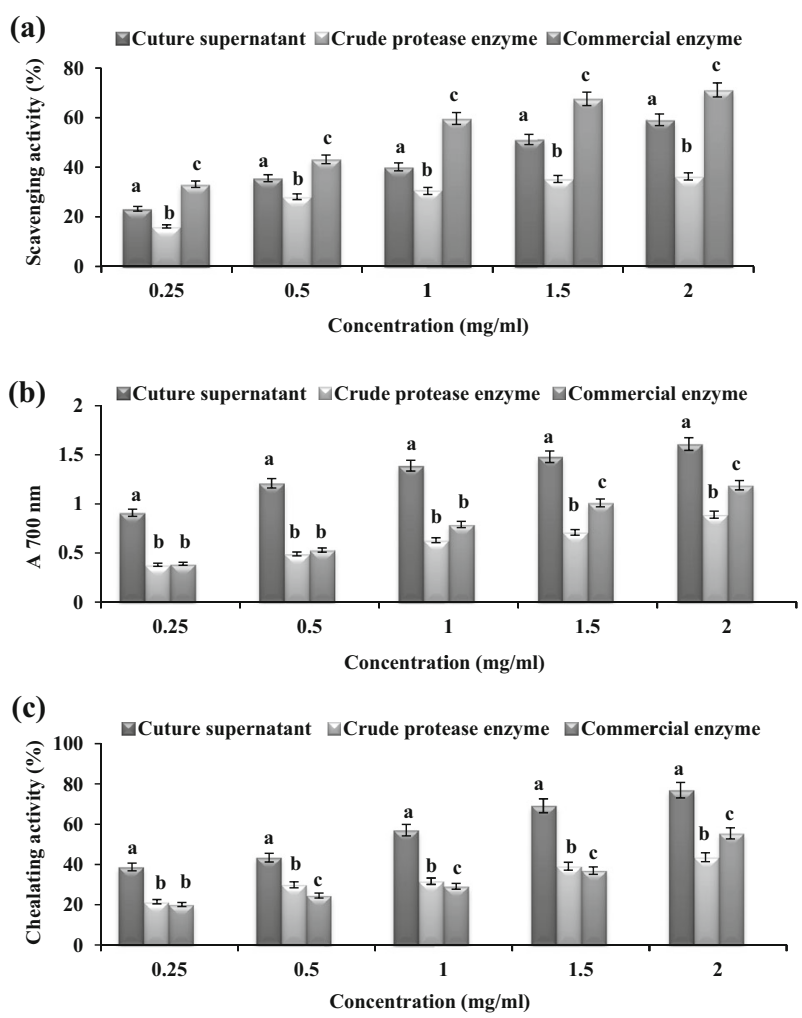

Fig. 7 Antioxidant activity of crustacean shell waste. a Effect of DPPH scavenging activity by different concentrations of shrimp shell substrate. b Reducing power. c Metal chelating activity. Each value represents the mean of three experiments and the error bars indicate \pm SD. Bars having different alphabets at the respective concentrations are statistically significant $(P<0.05)$

The reducing power assay could be used to evaluate the ability of antioxidant to transfer electron or hydrogen (Yildirim et al. 2003). Similar to this study, Ghorbel-Bellaaj et al. (2012) examined the reducing power of tested hydrolysates (strain RP1, A26, A21, An6 and SV1) increased with increasing concentrations $(0.25-2 \mathrm{mg} / \mathrm{ml})$ along with the culture supernatant of strain A1 (B. pumilus). The highest activity (DO $700 \mathrm{~nm}=1.55$ at $1.5 \mathrm{mg} /$ $\mathrm{ml}$ ) was found in hydrolysate produced by A1 bacterial strain. Recently, the maximum reducing power activity (DO $700 \mathrm{~nm}=1.71$ at $2.0 \mathrm{mg} / \mathrm{ml}$ ) in shrimp shell hydrolysate produced by culture supernatant from Bacillus sp. APCMST-RS7 was also reported (Maruthiah et al. 2015). The reducing power could mainly be attributed to the bioactive compounds associated with antioxidant activity (He et al. 2000). These bioactive compounds might be present in the shrimp waste fermented supernatant, including phenolics, oligopeptides, or chitooligosaccharides; they are good electron donors and can terminate the radical chain reactions by converting free radicals to more stable products (Ghorbel-Bellaaj et al. 2012).

Metal chelation can result in prevention of metal redox cycling, occupation of all metal coordination sites, formation of insoluble metal complex, steric hindrance of interaction between metals, and formation of lipid intermediates (Hider et al. 2001; Moridani et al. 2003). Similar to this study, shrimp shell hydrolysate obtained with $B$. licheniformis RP1 exhibited the highest (98\% at $5 \mathrm{mg} / \mathrm{ml}$ ) ferrous chelating activity (Ghorbel-Bellaaj et al. 2012). Similarly, our previous study also reported the maximum chelating activity (98\% at $5 \mathrm{mg} / \mathrm{ml}$ ) obtained with shrimp shell hydrolasate with Bacillus sp. APCMST-RS7. Because ferrous ions are the most effective pro oxidants, the highest chelating ability of the APCMST-RS7 culture supernatant would be beneficial (Maruthiah et al. 2015). The difference between DPPH scavenging, reducing power and ferrous ion chelating abilities might be related to the different antioxidant compounds present in the culture supernatants. Still the exact mechanism of radical scavenging activity is not clear, it is attributed to amino and hydroxyl groups reacting with unstable free radicals, which facilitate formation of stable macromolecule radicals.

\section{Conclusion}

Low cost protease production, through microbial reclamation of marine wastes seems to be a judicious approach because of its eco-friendly nature. The production of inexpensive proteinolytic enzymes not only solves environmental problems, but also promotes the economic value and utilization of marine wastes. The remarkable properties of halophilic organic solvent tolerant protease produced by A. faecalis APCMST-MKW6 such as temperature, $\mathrm{pH}$ and $\mathrm{NaCl}$ tolerance and also compatibility with surfactants, metals will make this enzyme as a potential product for the development of sustainable industrial process for waste management. Also, deproteinization and antioxidants properties of shrimp shell hydrolasate showed further industrial applications of the HOSP of APCMST-MKW6.

Acknowledgments The authors also gratefully acknowledge the University Grants Commission (UGC), New Delhi, Government of India, for its financial support in the form of Basic Science Research Scheme (UGC NO. F.7-374/2012 (BSR) dated March 2014).

\section{Compliance with ethical standards}

Conflict of interest The authors declare that there is no conflict of interest on publication of this article.

Open Access This article is distributed under the terms of the Creative Commons Attribution 4.0 International License (http:// creativecommons.org/licenses/by/4.0/), which permits unrestricted use, distribution, and reproduction in any medium, provided you give appropriate credit to the original author(s) and the source, provide a link to the Creative Commons license, and indicate if changes were made. 


\section{References}

Annamalai N, Rajeswari MV, Thavasi R, Vijayalakshmi S, Balasubramanian T (2012) Optimization, purification and characterization of novel thermostable, haloalkaline, solvent stable protease from Bacillus halodurans CAS6 using marine shellfish wastes: a potential additive for detergent and antioxidant synthesis. Bioprocess Biosyst Eng 36:873-883

Annamalai N, Rajeswari MV, Thavasi R, Vijayalakshmi S, Balasubramanian $T$ (2013) Optimization, purification and characterization of novel thermostable, haloalkaline, solvent stable protease from Bacillus halodurans CAS6 using marine shellfish wastes: a potential additive for detergent and antioxidant synthesis. Bioprocess Biosyst Eng 36:873-883

Annamalai N, Rajeshwari MV, Sahu SK, Balasubramanian T (2014a) Extraction, purification and application of thermostable and halostable alkaline protease from Bacillus alveayuensis CAS 5 using marine wastes. Food Bioprod Process 92:335-345

Annamalai N, Rajeshwari MV, Sahu SK, Balasubramanian T (2014b) Purification and characterization of solvent stable, alkaline protease from Bacillus firmus CAS7 by microbial conversion of marine wastes and molecular mechanism underlying solvent stability. Process Biochem 49:1012-1019

Doukyu N, Ogino H (2010) Organic solvent-tolerant enzymes. Biochem Eng J 48:270-282

Garcia-Carreno FC, Dimes CE, Haard NF (1993) Substrate gel electrophoresis for composition and molecular weight of proteinases of proteinaceous proteinase inhibitor. Anal Biochem 214:65-69

Ghorbel-Bellaaj O, Hana Maalej IY, Hajji S, Nasri M (2012) Chitin extraction from shrimp shell waste using Bacillus bacteria. Int $\mathrm{J}$ Biol Macromol 51:1196-1201

Haddar A, Hmidet N, Ghorbel-Bellaaj O, Fakhfakh-Zouari N, Sellami-Kamoun A, Nasri M (2011) Alkaline proteases produced by Bacillus licheniformis RP1 grown on shrimp wastes: application in chitin extraction, chicken feather-degradation and as a dehairing agent. Biotechnol Bioche Eng 16:669-678

Hajji S, Ghorbel-Bellaaj O, Younes I, Jellouli K, Nasri M (2015) Chitin extraction from crab shells by bacillus bacteria. Biological activities of fermented crab supernatants. Int $\mathrm{J}$ Biol Macromol 79:167-173

He ZD, Lau KM, Xu HX, Li PC, But PPH (2000) Antioxidant activity of phenylethanoid glycosides from Brandisia hancei. J Ethnopharmacol 71:483-486

Hider RC, Liu ZD, Khodr HH (2001) Metal chelation of polyphenols. Methods Enzymol 335:190-203

Islam MS, Khan S, Tanaka M (2004) Waste loading in shrimp and fish processing effluents: potential source of hazards to the coastal and nearshore environments. Mar Pollut Bull 43:103-110

Jellouli K, Ghorbel-Bellaaj O, Ayed HB, Manni L, Agrebi R, Nasri M (2011) Alkaline-protease from Bacillus licheniformis MP1: purification, characterization and potential application as a detergent additive and for shrimp waste deproteinization. Process Biochem 46:1248-1256
Karan R, Khare SK (2011) Stability of haloalkaliphilic Geomicrobium sp. protease modulated by salt. Biochemistry 76:686-693

Laemmli DK (1970) Cleavage of structural proteins during the assembly of the head of bacteriophage T4. Nature 227:680-685

Manni L, Jellouli K, Ghorbel-Bellaaj O (2010) An oxidant- and solvent-stable protease produced by Bacillus cereus SV1: application in the deproteinization of shrimp wastes and as a laundry detergent additive. Appl Biochem Biotechnol 160:2308-2321

Maruthiah T, Esakkiraj P, Immanuel G, Palavesam A (2014) Alkaline serine protease from Bacillus fluxus AP-CMST-RS2P: purification and characterization. Curr Biotechnol 3:2211-5501

Maruthiah T, Immanuel G, Palavesam A (2015) Purification and characterization of halophilic organic Solvent tolerant protease from marine Bacillus sp. APCMST-RS7 and its antioxidant potentials. Proc Natl Acad Sci India Sect B Biol. doi:10.1007/ s40011-015-0603-0

Moridani MY, Pourahmad J, Bui H, Siraki A, Brien OPJ (2003) Dietary flavonoid iron complexes as cytoprotective superoxide radical scavengers. Free Rad Biol Med 34:243-253

Rahman RNZRA, Geok LP, Basri M, Salleh AB (2006) An organic solvent-stable alkaline protease from Pseudomonas aeruginosa strain K: enzyme purification and characterization. Enzyme Microb Technol 39:1484-1491

Rajkumar R, Jayappriyan KR, Rengasamy R (2011) Purification and characterization of a protease produced by Bacillus megaterium RRM2: application in detergent and dehairing industries. J Basic Microbiol 51:614-624

Raut GR, Chakraborthy S, Chopade BA, Kolkare CR (2013) Isolation and characterization of organic solvent tolerant protease from alkaliphilic marine Saccharopolyspora species. Ind J Biotechnol 42:131-138

Sachindra NM, Bhaskar N, Mahendrakar NS (2005) Carotenoids in different body components of Indian shrimps. J Sci Food Agric 85:167-172

Shah K, Mody K, Keshri J, Jha B (2010) Purification and characterization of a solvent, detergent and oxidizing agent tolerant protease from Bacillus cereus isolated from the Gulf of Khambhat. J Mol Catal B Enzym 67:85-91

Sinha R, Khare SK (2012) Isolation of a Virgibacillus sp. EMB13: characterization of its protease for detergent application. Indian J Biotechnol 11:416-426

Takami H, Akiba T, Horikaoshi K (1989) Production of extremely thermostable alkaline protease from Bacillus Sp. No. AH-101. Appl Microbiol Biotechnol 30:120-124

Yang JK, Shih IL, Tzeng YM, Wang SL (2000) Production and purification of protease from a Bacillus subtilis that can deproteinize crustacean wastes. Enzyme Microb Technol 26:406-413

Yildirim M, Baysal V, Serhat Inaloz H, Kesici D, Delibas N (2003) the role of oxidants and antioxidants in generalized vitiligo. J Dermatol 30:104-108 